\title{
EMPRESÁRIOS BRASILEIROS NOS ESTADOS UNIDOS
}

\author{
Ana Cristina O. Siqueira *
}

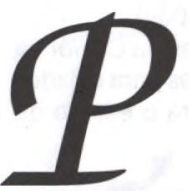

esquisas recentes sobre os imigrantes brasileiros nos Estados Unidos nos fornecem informações valiosas sobre a atuação dos brasileiros como empresários (Martes, 2000, 2001; Sales, 2003; Werneck, 2004). Sales (2003) informa que os brasileiros residentes na região de Boston e na cidade de Framingham, Massachusetts, têm uma forte atuação empresarial. Werneck (2004) reporta a existência de cerca de 350 empresas brasileiras em Massachusetts, as quais geram em torno de 180 milhões de dólares em impostos estaduais, contribuindo para o desenvolvimento econômico de cidades como Framingham.

No entanto, apesar de ter produzido uma gama de excelentes estudos, a pesquisa sobre os brasileiros nos Estados Unidos se concentra na maior parte das vezes em levantamentos baseados em um pequeno número de entrevistados (por exemplo, Martes, 2000). Como as conclusões são derivadas em sua maioria de amostras não probabilísticas, os resultados não podem ser considerados como representativos da população brasileira nos Estados Unidos. Desse modo, a pesquisa sobre os brasileiros nos Estados Unidos pode ser enriquecida através de estudos baseados em dados de larga-escala, produzidos através de amostras probabilísticas, como os do censo. Neste artigo, eu apresento evidência sobre empresários brasileiros nos Estados Unidos com base no censo norte-americano. Eu avalio a representatividade do censo com relação aos imigrantes brasileiros na próxima seção.

\section{IMIGRANTES BRASILEIROS E A REPRESENTATIVIDADE DO CENSO NORTE- AMERICANO}

Diversos estudos sobre imigrantes brasileiros nos Estados Unidos enfatizam a idéia de que o censo subestima o número de brasileros no país (Beserra, 2003; DeBiaggi, 2002; Margolis, 1998, 2003; Martes, 2000; Sales, 2003). No entanto, eu proponho uma outra perspectiva sobre este assunto ao recorrer a diferentes métodos. Primeiro, eu elaboro uma comparação entre as estimativas do censo e as do Ministério das Relações Exteriores (MRE) para o número de brasileiros nos Estados Unidos. Nesta comparação, eu incluo imigrantes de primeira geração bem como aqueles de segunda geração, o mesmo critério usado pelo MRE em suas estimativas.
Ou seja, eu incluo brasileiros nascidos no Brasil e aqueles nascidos em outros países ou nos Estados Unidos, os últimos também chamados de Brazilian-Americans. BrazilianAmericans constituem, de acordo com o censo, cerca de $16 \%$ dos brasileiros nos Estados Unidos. Finalmente, eu agrupo geograficamente as estimativas do censo conforme o critério do MRE referente às areas de jurisdição dos consulados (Brazilian Embassy in Washington, DC, 2005). A Tabela 1 apresenta os resultados.

$$
* * *
$$

O censo representa mais de cem por cento do número de brasileiros estimado pelo MRE na jurisdição consular de Chicago, como mostra a Tabela 1. Deste modo, se as estimativas do MRE estão corretas, estudos baseados em dados do censo para esta jurisdição consular devem ter uma alta representatividade - ao contrário da idéia divulgada na atual literatura acadêmica.

Além disso, o censo representa cerca de $63 \%$ dos brasileiros nas juridições consulares de Los Angeles e São Francisco, e em torno de $44 \%$ dos brasileiros na jurisdição consular de Miami. Este grau de representatividade é significativo, 
particularmente se considerarmos a possibilidade dos dados do MRE estarem superestimados. Martes (2000) informa que o MRE nos anos 90 usou estimativas da Arquidiocese de Boston, as quais por sua vez basearam-se em estimativas informais de agências de viagens e remessas de dinheiro, de maneira que pode ter ocorrido sobreposição de dados. Como os dados do MRE podem estar superestimados em algumas regiões, é razoável supor que os dados do censo possam ser representativos dos brasileiros nas jurisdições consulares de Miami, Los Angeles, e São Francisco, onde o censo representa uma grande proporção das estimativas do MRE. ${ }^{1}$ Portanto, é possível que dados do censo para as jurisdições consulares de Chicago, Miami, Los Angeles, e São Francisco possam representar a população brasileira nestas regiões.

\section{DADOS E AMOSTRA}

Eu uso dados de uso público do censo 2000 norte-americano (Ruggles et al., 2004). Eu limito a amostra aos estados da Flórida e Califórnia, ${ }^{2}$ regiões em meio a um grande fluxo de imigração (Waters, 1999). Subsequentemente, eu limito a amostra a brasileiros na condição de responsáveis pelo domicílio, morando em áreas metropolitanas, com pelo menos 18 anos, e ativos na força de trabalho civil e remunerada.

Além disso, eu estabeleço um ponto de corte excluindo da amostra os indivíduos que ganham anualmente menos de 5 mil dólares provenientes de suas empresas (Bates, 1997). Este ponto de corte é necessário porque o censo classifica trabalhadores com múltiplas fontes de emprego de acordo com a relação de emprego na qual eles trabalharam por mais horas na semana de referência do censo. Desse modo, um indivíduo que ganha anualmente menos de 5 mil dólares através do seu negócio e declara ser um dono de negócio pode, na verdade, ser um trabalhador assalariado que trabalha ocasionalmente como empresário (Bates, 1997). Indivíduos que trabalham em um emprego assalariado e, esporadicamente, como empresários são propensos a apresentar condições de trabalho específicas, as quais merecem uma análise em separado. $\mathrm{O}$ ponto de corte ajuda a prevenir o risco de incluir no estudo pessoas que trabalham ocasionalmente como empresários entre os donos de negócio. Este estudo considera como donos de negócio as pessoas que se encaixam nos critérios de seleção da amostra mencionados no parágrafo anterior e que ganham anualmente pelo menos 5 mil dólares através de suas empresas. A Tabela 2 mostra as ocupações mais frequentes entre os donos de negócio.

\section{$* * *$}

A ocupação mais comum entre os empresários brasileiros é a de trabalhador no ramo de limpeza de casas, como revela a Tabela 2 . Na Flórida, limpadores de casas e edifícios representam cerca de $29 \%$ dos empresários. Na Califórnia a ocupação mais frequente também é no ramo de limpeza de casas, representando cerca de $15 \%$ dos empresários. Importantes conclusões ficam evidentes ao examinarmos a distribuição dos empresários conforme o grau de escolaridade através da tabela 3.

$$
* * *
$$

Uma parcela expressiva dos empresários brasileiros tem curso superior completo ou pós-graduação, tanto na Califórnia (52\%) quanto na Flórida (48\%), como mostra a Tabela 3. Esta parcela é ainda maior entre os empresários no ramo de limpeza de casas na Califórnia, dos quais $66 \%$ tem curso de graduação ou pós-graduação. Na Flórida, 38\% dos empresários no ramo de limpeza de edifícios tem graduação ou pós-graduação, e entre 
os empresários no ramo de limpeza de casas, dos quais a vasta maioria é composta por mulheres, $29 \%$ tem curso superior ou pós-graduação. Este resultado parece refletir o fato de que muitos imigrantes brasileiros nos Estados Unidos trabalham em empregos aquém de suas aptidões profissionais ou de forma inconsistente com o seu nível educacional (Sales, 1995). Por exemplo, Fleischer (2002) reporta o caso de brasileiros imigrantes com curso superior trabalhando na limpeza de casas. Esta situação de discrepância entre a preparação educacional e a posição ocupacional aparece, portanto, retratada também no censo.

\section{CONCLUSÃO}

Este estudo mostra que a ocupação mais frequente entre os empresários
Tabela 2 - Ocupações Mais Frequentes entre Empresários Brasileiros: Flórida e Califórnia, 2000

\begin{tabular}{|ll|}
\hline Estado & \multicolumn{1}{c|}{ Ocupações Mais Frequentes } \\
\hline & Trabalhadores no Ramo de Limpeza de Casas (25\%) \\
& Supervisores/Gerentes de Vendedores no Ramo de Varejo (8\%) \\
& Trabalhadores no Ramo de Limpeza de Edifícios (4\%) \\
& Trabalhadores em Serviço de Babá (4\%) \\
Flórida & Motoristas de Caminhão ou Entrega de Mercadorias (4\%) \\
& Trabalhadores no Ramo de Construção (3\%) \\
& Advogados (3\%) \\
& Trabalhadores no Ramo de Limpeza de Casas (15\%) \\
& Gerentes, Outros (7\%) \\
& Cabeleireiros e Cosmetologistas (5\%) \\
& Supervisores/Gerentes no Ramo de Construção (5\%) \\
& Fotógrafos (5\%) \\
& Programadores de Computador (5\%) \\
& Designers (5\%) \\
&
\end{tabular}

Fonte: Censo 2000 dos Estados Unidos, amostra de 5 por cento (Ruggles et al., 2004).

Nota: Os números entre parênteses são porcentagens relativas ao número estimado de empresários brasileiros em cada estado. Número estimado de empresários brasileiros na Flórida $=1.209$, número de empresários brasileiros na Califórnia $=783$, conforme ponto de corte e critério de seleção da amostra. Dados com aplicação de peso estatístico.

Tabela 3 - Escolaridade e Gênero dos Empresários Brasileiros: Flórida e Califórnia, 2000

\begin{tabular}{|c|c|c|c|c|c|}
\hline Estado & Ocupação & Gênero & $\%$ & Escolaridade a & $\%$ \\
\hline \multirow{3}{*}{ Flórida } & Todos & $\begin{array}{l}\text { Mulheres } \\
\text { Homens }\end{array}$ & $\begin{array}{l}37 \\
63\end{array}$ & $\begin{array}{l}\text { Segundo grau incompleto } \\
\text { Segundo grau completo } \\
\text { Curso superior completo }\end{array}$ & $\begin{array}{l}15 \\
37 \\
48\end{array}$ \\
\hline & Limpeza de Casas & $\begin{array}{l}\text { Mulheres } \\
\text { Homens }\end{array}$ & $\begin{array}{r}92 \\
8\end{array}$ & $\begin{array}{l}\text { Segundo grau incompleto } \\
\text { Segundo grau completo } \\
\text { Curso superior completo }\end{array}$ & $\begin{array}{l}27 \\
44 \\
29\end{array}$ \\
\hline & Limpeza de Edifícios & $\begin{array}{l}\text { Mulheres } \\
\text { Homens }\end{array}$ & $\begin{array}{l}38 \\
62\end{array}$ & $\begin{array}{l}\text { Segundo grau incompleto } \\
\text { Segundo grau completo } \\
\text { Curso superior completo }\end{array}$ & $\begin{array}{l}-- \\
62 \\
38\end{array}$ \\
\hline \multirow[t]{2}{*}{ Califórnia } & Todos & $\begin{array}{l}\text { Mulheres } \\
\text { Homens }\end{array}$ & $\begin{array}{l}34 \\
66\end{array}$ & $\begin{array}{l}\text { Segundo grau incompleto } \\
\text { Segundo grau completo } \\
\text { Curso superior completo }\end{array}$ & $\begin{array}{l}-- \\
48 \\
52\end{array}$ \\
\hline & Limpeza de Casas & $\begin{array}{l}\text { Mulheres } \\
\text { Homens }\end{array}$ & $\begin{array}{l}79 \\
21\end{array}$ & $\begin{array}{l}\text { Segundo grau incompleto } \\
\text { Segundo grau completo } \\
\text { Curso superior completo }\end{array}$ & $\begin{array}{l}-\cdot \\
34 \\
66\end{array}$ \\
\hline
\end{tabular}

Fonte: Censo 2000 dos Estados Unidos, amostra de 5\% (Ruggles et al., 2004).

Nota: $\%=$ percentual relativo ao número de brasileiros no citado grupo ocupacional em cada estado.

a Segundo grau incompleto ou menor nível de escolaridade; segundo grau completo ou superior incompleto; curso superior completo ou pós-graduação.

Número estimado de empresários brasileiros na Flórida: total = 1.209: na limpeza de casas $=301$ e na limpeza de edifícios $=52$; número estimado de empresários brasileiros na Califórnia: total $=783$, e na limpeza de casas $=114$; conforme ponto de corte e critério de seleção da amostra. Dados com aplicação de peso estatístico. 
brasileiros na Califórnia e Flórida é no ramo de limpeza de casas. Zsembik (2000, p.235) enfatiza a idéia de que "as economias metropolitanas da Flórida parecem ser suficientemente diversas e dinâmicas para absorver relativamente grandes fluxos migratórios internacionais e internos de latinos e latino-americanos." 3 Porém, embora a economia da Flórida tenha proporcionado aos brasileiros oportunidades de atuação como empresários, vários deles parecem restritos a posições empresariais de baixo status ocupacional. Como Martes (2000, p.101) coloca, "chamar a faxina doméstica de business pode ser interpretado como um eufemismo que visa a encobrir o rebaixamento do status ocupacional que o imigrante desfrutava no Brasil."

A atividade empresarial de brasileiros, no entanto, estende-se além da limpeza de casas e edifícios em um gama de ocupações e setores econômicos. A expansão das empresas brasileiras produz resultados econômicos que podem trazer consequências positivas não só para a comunidade brasileira mas também para outras comunidades locais e grupos empresariais. Por exemplo, Sales (2003) destaca o fato de que associações profissionais e bancos de Massachusetts demonstram interesse em estabelecer vínculos com a promissora comunidade empresarial brasileira na região. Pesquisas futuras poderiam estudar o desenvolvimento de redes sociais ligando agentes da comunidade econômica a empresários brasileiros na Califórnia e Flórida e o papel destas redes em beneficiar a expansão de empresas brasileiras nos Estados Unidos.

* Ana Cristina o. Siqueira é Mestranda em Sociologia na Universidade da Flórida.

\section{NOTAS}

1 - É possível que os dados do censo subestime seletivamente imigrantes sem documentação. Se imigrantes não autorizados estiverem sub-representados nos dados, o censo pode refletir principalmente a situação da população de imigrantes em condições legais. Porém, como o censo entrevista a população em geral, incluindo imigrantes não documentados, e não registra informações sobre status legal, não é possivel determinar com certeza a magnitude desta potencial subrepresentação.

2 - Cerca de $71 \%$ dos brasileiros na jurisdição consular de Los Angeles e São Francisco encontram-se no estado da Califórnia, e em torno de $82 \%$ dos brasileiros na jurisdição consular de Miami encontram-se no estado da Flórida.

3 - Tradução da autora.

\section{REFERÊNCIAS BIBLIOGRÁFICAS}

BATES, Timothy

(1997) Race, Self-Employment, and Upward Mobility: An Illusive American Dream. Baltimore, MA: Johns Hopkins University Press.

BESERRA, Bernadete

(2003) Brazilian Immigrants in the United States: Cultural Imperialism and Social Class. New York: LFB Scholarly Publishing [livro eletrônico]. BRAZILIAN EMBASSY IN WASHINGTON, DC

(2005) "List of Consular Jurisdictions in the United States." Washington, DC: Brazilian Embassy. Retrieved November 17, 2005 (http:// www.brasilemb.org/consulado/ consular_jurisdictions.shtml).

DEBIAGGI, Sylvia D. D.

(2002) Changing Gender Roles: Brazilian Immigrant Families in the U.S. New York: LFB Scholarly Publishing.

FLEISCHER, Soraya R.

(2002) Passando a América a Limpo: O Trabalho de Housecleaners Brasileiras em Boston, Massachusetts. São Paulo: Annablume.

MARGOLIS, Maxine L.
(1998) An Invisible Minority: Brazilians in New York City. Boston, MA: Allyn and Bacon.

MARGOLIS, Maxine L.

(2003) "Na Virada do Milênio: A Emigração Brasileira para os Estados Unidos." In: MARTES, Ana Cristina B. and FLEISCHER, Soraya. Fronteiras Cruzadas: Etnicidade, Gênero e Redes Sociais. São Paulo: Editora Paz e Terra, pp. 51-72.

MARTES, Ana C. B.

(2000) Brasileiros nos Estados Unidos: Um Estudo sobre Imigrantes em Massachusetts. São Paulo: Paz e Terra.

MARTES, Ana C. B.

(2001) Empresários Brasileiros em Boston. São Paulo: EAESP.

RUGGLES, Steven; SOBEK, Matthew; ALEXANDER,Trent; FITCH, Catherine A.; GOEKEN,Ronald; Patricia Kelly, HALL; KING, Miriam and RONNANDER, Chad (2004) Integrated Public Use Microdata Series: Version 3.0 [Machine-readable database]. Minneapolis, MN: Minnesota Population Center [producer and distributor]. Retrieved November 12, 2005 (http://www.ipums.org).

\section{SALES, Teresa}

(1995) "O Trabalhador Brasileiro no Contexto das Novas Migrações Internacionais". In: PATARRA, Neide L. 1995. Emigração e Imigração Internacionais no Brasil Contemporâneo. São Paulo: FNUAP, pp. 90-103.

\section{SALES, Teresa}

(2003) Brazilians Away from Home. New York: Center for Migration Studies.

WATERS, Mary C.

(1999) "Immigrant Dreams and American Realities: The Causes and Consequences of the Ethnic Labor Market in American Cities." Work and Occupations 26, n으 3, pp. 352-364.

WERNECK, José I.

(2004) Com Esperança no Coração: Os Imigrantes Brasileiros nos Estados Unidos. São Paulo: Augurium Editora.

ZSEMBIK, Barbara A.

(2000) "The Cuban Ethnic Economic and Labor Market Outcomes of Latinos in Metropolitan Florida." Hispanic Journal of Behavioral Sciences 22, № 2, pp. 223-236. 